\title{
Improving Pre-Service Teachers' Performance in the Teaching of Common Fraction Using Cuisenaire Rods
}

\author{
AMOAH, DANIEL ${ }^{*}$ MED. AUGUSTINE ADJEI ${ }^{1}$ MPHIL/MED \\ *Berekum College of Education, Brong Ahafo Region-Ghana West Africa \\ 1 Offinso College of Education, Ashanti Region-Ghana West Africa
}

\begin{abstract}
This research study was undertaken to assess the difficulties pre-service teachers face using Cuisenaire Rods in teaching Common Fractions and how often these concrete models are used in their mathematics lessons. The extent of pupils' participation and understanding the basic concept of common fractions, the student-teachers' preference of using Cuisenaire Rods as against the use of fractional rules in teaching common fractions formed the integral part of the research study. Action research design was used for this study. The design allows the researcher to obtain answers to the questions raised directly from the respondents. The target population was pre-service teachers of Berekum College of Education. Random sampling procedure was used to select 50 student-teachers and JHS2 pupils as sample for the study so as to enhance the validity and generalization of the result. Observation of studentteachers' teaching practices, model teaching by the researcher, questionnaire, and interviews granted to pupils on the study of common fraction on the use of Cuisenaire Rods were among the research instruments used. Descriptive statistics in terms of frequencies with their percentages were also used in analyzing the data obtained from the questionnaire. The research findings revealed that the use of Cuisenaire Rods to teach Common Fractions stimulates motivates and arouses the interest of learners to participate fully in the teaching and learning process. This helps pupils to actively partake in learning basic concepts in mathematics whenever concrete models were used in the lesson presentation. The research findings strongly indicated that no matter how different the preservice teachers are prepared; the competencies of teacher education in our contemporary world would much depend on student-teachers' teaching methods and teaching practices that can bring real meaning into the lives of their pupils. It is recommended that the supply of mathematics syllabus into the Colleges of Education should be accompanied with adequate teaching and learning aids for pre-service teachers. This would allow them to receive sufficient pre-training in all aspects of the curriculum before becoming professional teachers
\end{abstract}

DOI: $10.7176 / \mathrm{JEP} / 10-9-01$

Publication date:March $31^{\text {st }} 2019$

\section{Background to the Study}

The world is growingat a faster rate as a result of the increasing development in almost all areas of life based on effective knowledge of mathematics, science and technology. Accordingly, there cannot be any meaningful development in any area of life without the knowledge of mathematics. It is for this reason that the educational systems of various countries that are concerned about their development put greater emphasis on the study of mathematics.Riddle and Rodzwell (2000) found that young children have a beginning understanding of fraction concepts. They however contended that, in many instances, educators ignore this powerful intuitive knowledge, and as a result, students learn computation of fractions by rote. The authors concluded that although students must eventually understand the standard algorithms, "children should start by using their understanding of fractions to develop procedures that make sense to them". With regard to their assertion, there is no doubt that wrong approach to teaching of mathematics makes the learning of mathematics difficult to pupils. The results are that many pupils fail in mathematics examinations which eventually lead to their dislike of the subject.

Mathematics at the primary school level in Ghana emphasizes knowledge and skills that will help the pupil to develop the foundation for numeracy. Pupils learn mathematics to assist in their daily activities like trading which include buying and selling. In view of this, pupils are expected to read and used number competently, reason logically, solve problems and communicate effectively using mathematics ideas. It is in the light of this that the researcher has taken the trouble to help guide pre-service teachers to use hands-on activity to teach common fractions at the basic school level.Although, young children have useful ideas about fractions, these intuitions do not automatically develop into a strong understanding of fraction concepts necessary for success in the Junior High school level. In fact, Anderson and Wenzel (2000) noted that many students have poor understanding of fraction concepts, as well as the inability to recognize accurate visual representations of fractions. They describe a range of activities using oil and water to demonstrate the equivalence of fractions, as well as the addition and subtraction of fractions. As a result of these explorations, their students gained "a deeper understanding of fractions both visually and through hands-on activity.

Fractions are a basic building block in the foundation of mathematics. Students need a good understanding of the concepts of fractions, in order to be comfortable performing operations with them as they move on to higher mathematics. It is therefore the researcher's view that a critical examination into the problem in Mathematics 
Teacher Education which seeks to help prospective professional teachers learn to teach mathematics is realised. As a mathematics teacher educator, my goal is to help my student-teachers learn to do something different and even better than what they experienced as students in mathematics classes. In addition, a case in point can be associated with the kinds of experiences with mathematics and with the teaching and learning of mathematics that my students teachers have had at their Senior Secondary School education before entering Teacher Training College and the ways in which those experiences influence the trajectories on which they move in becoming teachers in the near future.

There is therefore no doubt that when other teacher educators sometimes speak of pre-service teacher education as the first stage in learning to teach, nothing could be further from the truth. In fact, before they take their first professional course, future mathematics teachers have already clocked over 2,000 hours in a specialized "apprenticeship of observation" (Lortie, 1975) which has instilled not only traditional images of teaching and learning but has also shaped their understandings of mathematics. Thus, pre-service diploma teachers these days have their teaching practice within a period of almost one year in a selected basic school before graduating to become professional teachers. Basically, mathematics at the Junior High School in Ghana is built on the knowledge and competencies developed at the Primary School level. The pupils are expected at the Junior High School level to be able to move beyond and be able to use mathematics ideas in investigating real life situations. There is therefore no doubt that the strong mathematical competence developed at the basic schools level is a necessary requirement for effective study in mathematics, science, commerce, industry and variety of other professions.

In considering the problem, the researcher focused on the role of a method course in helping prospective basic teachers learn to teach mathematics. A method course is a particular curricular occasion, one that is different from other kinds of teacher education courses in some significant ways. It is about acquiring new ways of thinking about teaching and learning. But it is also about developing pedagogical ways of doing, acting and teaching. At this point, the teaching of common fractions brings into light its own set of issues, different from those in writing or social studies. The researcher's challenge with the use of hands-on activity is the extent to which the teaching method should have a positive influence in the direction student teachers move at any time they stand to handle common fractions before pupils at the basic schools, as they develop into teachers of mathematics.

Upon a number of trails of assisting students with diverse ways of teaching basic fraction skills, the researcher resolved adopting an instructional model of learning which is full of activities and games devoted to expose children to exploring fractional situations that occur in everyday situations. With this hands-on learning approach in the teaching and learning of common fractions, the pre-service teachers are equipped with the knowledge that mathematics is more meaningful when it is rooted in real life context and situations. They also come to understand that when children are given the opportunity to become actively involved in learning they acquire knowledge and skills, and develop an understanding of mathematics from their own experience.Therefore having in mind, these and other basic principles that govern the use and practice of hands-on activity of learning mathematics at the basic level of our schools in Ghana, it is the researcher's hope that the problem of pre-service teachers struggling to handle the teaching of common fractions could be overcome.

\section{Statement of the Problem}

Embarking on active learning in motivating contexts at the basic level of our schools in Ghana cannot be overemphasized. However, a critical observation on the mode of teaching common fractions by many mathematics teachers at our schools, especially in the training institutions has always been the traditional way of asking the students to acquire numerous pre-requisite content knowledge and to await the whole construction piece by piece of the cognitive edifice in order to perceive at last the end to the problem.In effect, such practices have made the mathematics classroom teachers to avoid their responsibilities which have inadvertently killed the pupils' motivation in the study of fractions. Therefore with these unwavering beliefs and practices coupled with the absence of structures that allow learners to create and build their own understanding of the topics they study, the roles of these pre-service teachers, who the society sees as future professional teachers, at the end of their course work, emerge as poor duplicators of mathematics methods instead of initiators of learning.

It is therefore clear to see that the products of future professional teachers who pass out at the Berekum College of Education are not exception, hence the mode of helping students teachers to acquire only the cognitive tool of teaching basic mathematics should give way to more constructivist view of learning where pupils see learning as their own drive based on hands-on activity and other activity based methods initiated by the mathematics teacher.

\section{Purpose of the Study}

Since the study of the basic concepts in mathematics is required at the basic level in our schools, there is the need to ensure that our children at the lower primary receive the good foundation in mathematics especially the basic operations on common fractions. The study therefore seeks to address an apparent gap between student teachers' Senior High School based knowledge of content and what they do in their teaching practises as regards 
mathematics lesson delivery with regard to the teaching of common fraction.Again, the study seeks to develop the type of experiences that will assist beginning teachers provide contextual teaching strategies where pupils can construct their own understanding in the study of mathematics. More importantly, the study seeks to improve beginning teachers with practice base knowledge that could serve as an effective vehicle for the translation of theory base knowledge into activity oriented technique of learning, where pupils' interest can be guaranteed to study mathematics, particularly on common fraction, without much difficulty.

\section{Research Questions}

The main objective of embarking on this research work is to find ways and means to improve the style of teaching common fractions at the basic level of our schools by pre-service teachers through the use of Cuisenaire Rods; hands-on activity, where children can learn and understand fractions better. In pursuit of this objective, the study sought to answer the following questions:

- How can the use of Cuisenaire Rods improve pre-service diploma teachers' performance in the teaching of common fraction?

- What types of teaching practices are needed by the pre-service teachers in order to overcome pupils' difficulties in the study of common fraction?

- What difficulties do pre-service teachers face in using Cuisenaire Rods to teach common fractions?

- To what extent can the use of Cuisenaire Rods by the pre-service teachers help improve pupils' mathematics achievement in the study of common fraction?

\section{Significance of the Study}

A major objective of the on-going educational reform programme is to improve the quality of teaching and learning. Since the teacher plays a pivotal role in the delivery of education, more attention must be directed towards guiding, directing and assisting the teacher to discharge his/her duties very efficiently. The significance of this study therefore, is to bring to light the problems and challenges pre-service teachers in the basic schools encounter in the teaching of Mathematics and in particular the task of imparting the easy learning and understanding of 'Common Fraction'. This would go a long way to help Mathematics teachers improve and adjust their teaching methods at the basic level of education.Also, the pupils who are at the centre of the study stand to benefit immensely through properly designed and supervised group work which would prevent the incidence of pupils learning mathematics instrumentally. Activity based learning is associated with a popular Chinese maxim, "if I hear, I forget, if I see, I remember but if I do, I understand". In order words, involving learners in activities make them remember and understand what they learn better.

More so, the experiences, knowledge and skills gained through the study would be useful to the researcher in catering for similar problems in the near future. Thus, the study seeks to develop effective strategies and techniques that would go a long way to facilitate and enhance pupils and teachers to understand the use of Cuisenaire Rods in the teaching and learning common fraction. It would equally be beneficial to head teachers, mathematics organizers, circuit supervisors and other resource persons who may find it expedient to organize seminars, workshops and inservice training programmes for primary school teachers. Above all, it would serve as a data base syllabus for primary schools that would affect policy makers and also draw the attention of other stakeholders in education to the teaching and learning of mathematics in general.

\section{Overview of Cuisenaire Rods}

Cuisenaire Rods are Rods of 10 different colours and lengths that are easy to handle. The Rods are versatile mathematical manipulatives used to help students independently discover basic mathematical principles rather than merely memorizing them. They are also used to teach a wide variety of mathematical topics such as the basic four operations, fractions, area, volume, square roots, solving simple equations, systems of equations and even quadratic equations. Again, they are used to teach elementary arithmetic properties such as commutative, associative and distributive properties. Though, Cuisenaire Rods are primarily used for mathematics in elementary schools as well as other levels of learning, they have also become popular in language-teaching in the classrooms. The Rods (reglettes in the original French) and named after their inventor, Georges Cuisenaire (1891-1976): a Belgian primary school teacher who published a book on their use in 1952 called 'les nombres en couleurs'. The use of the Rods for mathematics and language teaching was developed and popularized by Caleb Gatteqno in many countries around the world. The picture of 10 Rods measuring $1 \mathrm{~cm}$ to $10 \mathrm{~cm}$ can be found as figure 1 in appendix A.

\section{Theoretical Framework of the Study}

Many research works on learning theories done by recognized educationists and psychologists such as Jean Piaget, Zoltan Dienes and others have suggested for some time that children's concepts evolve through direct interaction with the environment, and as such manipulative materials provide a vehicle through which this can happen. Piaget 
(1971), in particular, suggested that concepts are formed by children through a reconstruction of reality, not through an imitation of it. He regarded intelligence as effective adaptation to one's environment. He also contended that evolution of intelligence involves the continuous organization and reorganization of one's perceptions of, and reactions to, the world around him.Perhaps the most important simple preposition that the educator can derive from Piaget's work, and its use in the classroom, is that children, especially young ones, learn best from concrete activities" (Ginsberg \&Opper, 1969, p.221). This preposition, if followed to its logical conclusion, would substantially alter the role of the classroom teacher from expositor to one of facilitator, that is, one who promotes and guides children manipulation and interaction with various aspects of their environment. The emphasis here is placed on the process dimension of the learning process and is at least as concerned with 'how' children learn as with 'what' it is they learn. Thus, the true understanding is given highest priority in the teaching and learning process. So it could be observed that the degree of meaning in the study of mathematics is maximized when individuals are allowed and encouraged to interact personally with various aspects of their environment.

Dienes (1971) in his constructivist principle of mathematics learning identified two kinds of thinkers: the constructive thinker and the analytic thinker. He roughly equates the constructive thinker with Piaget's concrete operational stage and the analytical thinker with Piaget's formal operational stage of cognitive development. The principle states that "construction should always precede analysis". It is analogous to the assertion that children should be allowed to develop their concepts in a global intuitive manner emanating from their own experiences. According to Dienes, these experiences carefully selected by the teacher form the cornerstone upon which all mathematics learning is based. Regarding the views expressed by these psychologists, I believe that, as a mathematics educator, mathematics learning is not a spectator, and as such, requires a very active type of physical and mental involvement on the part of the learner. Hence the mathematics teachers should endeavour to create classroom environment that would propel learners construct their own meaning out of the mathematics concept being learnt in the classroom and outside classroom.

\section{Using Cuisenaire Rods as manipulatives in mathematics learning}

Marsh and Cook (1996) studied the use of Cuisenaire Rods as a support for solving word problems with three third grade students with learning disabilities. The students were not only more successful at selecting the correct operation when using the manipulatives but continued to improve after the manipulatives were withdrawn. Students who use manipulatives in their mathematics classes usually outperform those who do not (Driscoll, 1983; Sowell, 1989; Suydam, 1986). This benefit holds across grade level, ability level, and topic, given that using a manipulative makes sense for the topic. Manipulative use also increases scores on retention and problem-solving tests. Finally, attitudes toward mathematics are improved when students are instructed with concrete materials by teachers knowledgeable about their use (Sowell, 1989).Wilensky (1991), found that depending on what kind of relationship the student has with the manipulative, an idea might be sensory-concrete, abstract, or integrated-concrete. The catch, however, is that mathematics cannot be packaged into sensory-concrete materials; no matter how clever our attempts are, because ideas such as number are not "out there." As Piaget has shown, they are constructions -reinventions -- of each human mind. "Fourness" is no more "in" four blocks than it is "in" a picture of four blocks. The child creates "four" by building a representation of number and connecting it with either real or pictured blocks (Clement, 1989; Clement and Battista 1990; Kamii 1973, 1985, 1986).

However, Moyer (2001) contended that teachers play an important role in helping students understand the concepts that manipulatives represent. This was highlighted in a 1-year study of 10 middle school mathematics teachers and their use of manipulatives. Teachers who were unable to represent mathematics concepts themselves were more likely to use manipulatives as a diversionary rather than instructional activity.Manipulatives by themselves have no inherent meaning. It is important for teachers to make this meaning explicit and help students build connections between the concrete materials and the abstract symbols that they represent. Thus, manipulatives enable students and teachers to represent concretely the abstract concepts that they are learning in mathematics class and to link these concepts to prior knowledge. Although they are used primarily in elementary schools, they offer a useful means to introduce new concepts to all students (Suh\& Moyer, 2007).For the most part, classroom use of manipulatives has involved concrete or physical manipulatives. A typical example is the use of Cuisenaire Rods which can easily be improvised and use in mathematics education at no cost in our basic schools. Cuisenaire Rods, as concrete manipulatives, help students improve their understanding of the abstract symbolic language of mathematics. The concrete manipulatives can also be used to clarify misconceptions and build connections between mathematical concepts and representations, fostering more precise and richer understanding.

Butler, et. al. (2003) research studies have evaluated the effectiveness of manipulatives as a tool in mathematics instruction. One line of their research work was on the study of the Concrete-RepresentationalAbstract (CRA) sequence of instruction; a form of explicit instruction that moves students from concrete manipulatives to pictorial representations of those manipulatives and finally to abstract concepts. The studies, again, compared the effectiveness of teaching fraction concepts to students with learning disabilities using a CRA approach versus a Representational-Abstract (RA) approach (starting with pictorial representations moving to 
abstract concepts, with no concrete manipulative). Fifty middle school students with mild to moderate disabilities were assigned to the CRA or the RA group. While both groups improved their understanding of fractions, the CRA group had overall higher scores than the RA group.Children need to conceptualize common fractions as quantities before they are introduced to conventional symbolic algorithms for adding, subtracting, multiplying and dividing fractions. As part of this quantitative understanding, students should know something about the relative size of different fraction and they should also know equivalents of one-half and other common fractions. For example, children may be given a fraction model with $2 / 3$ of a circle shaded and then asked to show that same fraction with a set of chips. Thus, emphasis should be placed on the use of multiple physical models of representations - pictorial, manipulatives, and verbal, real world, and symbolic in order to develop a deeper conceptual understanding in children about common fractions (Cramer, Post, \&delMas, 2002).

It is encouraging to teachers of traditionally under-served students to find that hands-on activity in mathematics learning possess potential to reach out to students for whom mathematics has hold little attraction. Clements and McMillen (1996) research revealed that using manipulatives can help children of all ages construct a deeper understanding of mathematics. Thus, the use of manipulatives or any hands-on activity causes teachers to emphasize and validate students' informal knowledge of mathematics, which all students have and which can promote a sense of mathematical and personal efficacy.Lesh (1979) has suggested that hands-on materials can be effectively used as an intermediary between the real world and the mathematical world. He contends that such use would tend to promote problem-solving ability by providing a vehicle through which children can model realworld situations. In support to Lesh's assertion, a lot of people are hands-on learners and it helps a lot for students to be able to work with something they can understand. Thus, manipulatives, especially using Cuisenaire Rods, work well in cooperative learning which allow students to take a more active role in classroom experiences; empowering students to not only learn, but teach also.

Figure 2

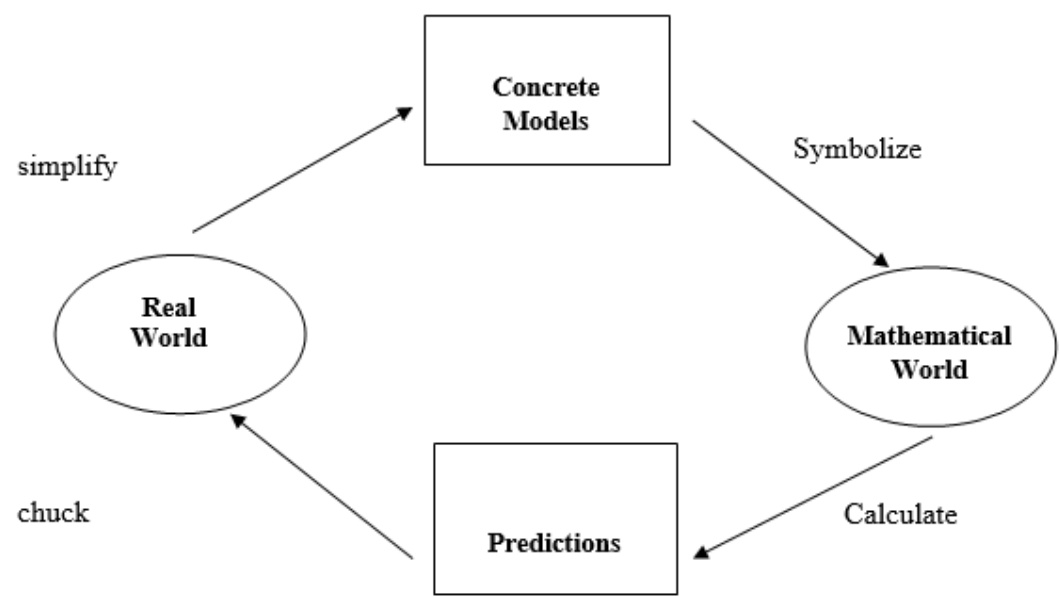

Figure 2 above illustrates Lesh's idea of bridging the gap between real world and mathematical world through the use of concrete materials.In terms of mathematics lesson delivery, from figure 1, hands-on activity may describe an activity where the concept taught is presented in a physical fashion; using concrete and semi-concrete manipulative which can provide children something real to reflect on. Even though the use of these hands-on materials or manipulatives such as the Cuisenaire Rods can be complex or as a simple as desired, their importance lies in being able to represent mathematical situations which are generally abstract. Here, children can then use their intuitive knowledge of how objects work concretely, or make observations of how those objects work, as a method of discovering, inventing, or coming to understand how the parallel abstract situations work. Under this related literature review, the researcher wish to state that most people are hands-on learners from the point view of their informal knowledge that has been developed at home before schooling. It is therefore hoped that students can be helped to build a strong conceptual base upon which they can rely, if Cuisenaire Rods are used to develop their quantitative understanding before symbolic ideas on common fractions are introduced, especially during early days of their basic education.

\section{Pre-service conceptual preparation of student-teachers}

Teaching is conceptualized as transmitting knowledge and promoting conceptual understanding. It is also seen as craft and artistry to solve the ambiguous problems of the classroom. These concepts about teaching strongly imply that the pre-service programmes with an academic perspective in the Colleges of Education in Ghana should focus on combining subject-matter courses and field experiences. Accordingly, Shulman (1987) contended that pedagogical-content knowledge has to do with the knowledge teachers need to have about teaching and students to teach effectively and more so be the trustworthy facilitator in classroom learning by promoting positive 
classroom atmosphere. It is in this light that the pre-service teacher education in our Colleges of Education should be tailored towards personal preparation. This should emphasize on pre-service students' interaction with teacher educators that provide the same personal interaction as the personal orientation encourages occurring between teachers and students. In addition, the pre-service programmes designed to prepare the would be teachers should focus on critical study of themes and direct experiences that help teachers understand the sociological influences which affect students (Feiman-Nemser, 1990).Carl (1969) made commentary on pre-service education and the ways in which teachers approach their students. Emphasizing on a client-centred approach to therapy, Rogers believed that the client had a better knowledge of what is needed to be done than the therapist, and so the therapist should be there simply to guide, encourage and be a resource to the client, rather than directing the client explicitly. His discoveries from the client-centred approach have it that the responsibility for all growth was placed upon the client. It was the client, who was making the decisions about what should be done during the therapy sessions, and so it was due to the client that success or failure was perceived to occur.

Commenting on the Rogers input, the researcher has no doubt in the mind that the mind-set of the pre-service teachers on teaching, especially Mathematics lessons must clearly be defined, in such a way that would be teacher should be properly trained to be the best facilitator who provides learning opportunities that learners create and build their own understanding of the topics they study, rather than having it delivered to them by teachers and written materials.

Feiman-Nemser (1990) expressed his views that the purposes of teaching are seem as educational and social leadership to promote a just, democratic society. To be able to put his views into practice, Feiman-Nemser suggested that pre-service education from the social point of view should emphasis on critical study of themes and direct experiences that help teachers understand the sociological influences which affect students' way of learning, particularly in mathematics.Overall in pre-service mathematics learning environment, student-teachers should be provided with ample learning opportunities to practice their mathematics skills. More often than not they need to know more about different classroom teaching and learning techniques that can be used; how to create participatory lessons that motivate children and keep them engaged in their classes.It is therefore the researcher's strong belief that when the mind-set of the pre-service diploma students are channelled in a professional way, they would tend to be reflective individuals who take ownership of their ideas and see them through from conceptualization to reality.

\section{Teaching and learning of common fractions}

A common or vulgar fraction is a mathematical expression usually written as a rational number having the numerator being an integer divided by a non-zero integer as its denominator. The introduction of fraction notation is a critical aspect of learning about common fraction. Ball (1992) observed that it is the teachers' role to assist students in the development of correct representations, as such there need to be a clear and direct mapping between the mode of external representation such as fraction name, the use of appropriate language and diagrams, and the formal symbol.In line with Ball's research findings, Lamon (2001) had it that there is evidence that the development of students' understanding of fractions is greatly enhanced by students developing their own representations of fraction ideas including pictorial, symbolic and spoken representations to clarify their thinking.Reflecting on both Ball (1992) and Lamon (2001) assertion, the researcher deduced that while building on the findings indicating the vital role teachers play in stimulating student learning, the focus on the role of the student should be recognized, such that students are not only recipients of the teachers' input but instead they actively participate in the learning process to construct meaning on their own. Therefore by gaining an understanding of the relationship between students' use of external representations in demonstrating their conceptual understanding of fractions, more effective use of external representations can be incorporated into instruction.

As many classroom teachers know, teaching and learning the various fraction operations can be difficult for many children in our basic schools. Many at times, it is not the concept of fraction that is difficult but rather it is the various operations, such as the addition, multiplication, subtraction, division and simplifying one does with fractions.Kamii and Clark (1995) contended that understanding fraction equivalence is important as it forms the foundation of understanding fraction addition and subtraction, and enables students to compare and order fractions. However, with the neglect of the right foundation of exposing students to the various fraction operations with the start of equivalent fraction, teachers resort to the rules of learning fractions which eventually makes it difficult for students to learn it.

With the use of rules in mathematics learning, children simply try to memorize them without knowing where they came from, and these rules would probably seem like a jungle of seemingly meaningless rules. The induction made here was that instead of merely presenting a rule as many textbooks do, a better way is to teach children to visualize fraction and perform some simple operations with some mathematical models or visual images without knowingly applying any given 'rule'. The table below sampled a number of 'rules' students learn about fractions: 
Table 1

Some rules of learning fractions

\begin{tabular}{l} 
Topic \\
\hline Fraction addition \\
(same denominators) \\
Fraction addition \\
(different denominators)
\end{tabular}

Finding equivalent Fraction same number Mixed number to a fraction

(Improper) fraction to a mixed number

Simplifying fractions

Fraction multiplication Fraction division

\section{Rule}

Add the numerators, and use the same denominator

first find a common denominator by taking the least

common multiple of the denominators. Then, convert all the addends to have this common denominator. Then, add using the rule above.

Multiply both the numerator and denominator with the

Multiply the whole number part by the denominator

and add the numerator to get the numerator. Use the same denominator as in the fractional part.

Divide the numerator by the denominator to get the whole number part. The remainder will be the numerator of the fractional part. Denominator is the same. Find the (greatest) common divisor of the numerator and denominator and divide both by it.

Multiply the numerators and the denominators

Find the reciprocal of the divisor and multiply by it.

A critical observation on the practice of using rules in the study of fraction as shown above revealed that traditional fraction-arithmetic instruction usually focuses on 'how' not on 'why'. Thus, even when the teachers correctly memorize the algorithms, most students do not understand the underlying rationale for adding or subtracting with unlike denominators and multiplying or dividing with fractions. As result, most children cannot give plausible justifications for the procedures they use (Peck \&Jenecks, 1981). The insight one discovers from the use of rules in solving problems of fractions is that if children understand where a particular formula comes from in a meaningful manner, they will be able to re-create it if and when they need it. Therefore, teachers should engage their students in more active teaching strategies in solving problems of fractions. With this activity method of teaching, students would be able to examine a problem, examine their resources, and find the ways in which resources can be used to meet the demands of the problem. In effect, learning how to think flexibly and allowing the same object to represent different quantities in different situations is an important part of growing in problem solving skills and developing abstract reasoning.

Golden and Shteingold (2001) stated that the fundamental to effective teaching and learning is the interaction between external and internal representation, with students interpreting teachers' external representation in a way which make sense to them. This goes to buttress the point that in a mathematics lesson delivery, the teacher should endeavour to take his pupils through the use of active learning strategies such as using manipulative models which help to build motivation in students in mathematics learning. It was therefore certain in the mind of the researcher that teachers' mathematical knowledge as well as their pedagogical content knowledge is critical factors in determining classroom practices. In their review of research, Ball et. al. (2001) reported that there is considerable evidence that teachers are less confident and less successful in teaching rational numbers than whole numbers. This was simply because whiles a number of fresh practicing teachers struggle with basic computations of fractions; others made errors in trying to apply a rule.

\section{Research Design}

Action research design was used for this study. This research design is systematic inquiry done by teachers (or other individuals in an educational setting) to gather information about, and subsequently improve, the ways their particular educational setting operates, how they teach, and how well their students learn (Mills, 2000). The action research design is the type of design used in solving a classroom problem or local school problem through application of scientific method. It is normally conducted in a local setting. To improve on how pre-service teachers teach common fractions using Cuisenaire Rods at the basic school level, the researcher relied on the use of action research design. The design, therefore, focused on pre-service teachers' teaching development as against pupils' mathematical learning and understanding of common fractions with the use of Cuisenaire Rods. The use of action research for this study is appropriate in the sense that it does not only enhance the teacher's professional status but also promotes teacher's personal development and improvement of his or her practice. The modern teacher needs to be equipped and to understand the various methods or approaches that best suit the pupils, he or she teaches. It is through this research design that the teacher can best evaluate his or her teaching effectively. The adoption of the research design is again appropriate because it provides the teachers with the opportunity to acquire better 
understanding of all aspect of their own practice in relation to subject, content curriculum or method appropriate to the level of pupils in the class. On the contrary, action research limits itself to the problem in the classroom, without making extension outside the classroom activities.

\section{Population}

Population refers to the target group about which the researcher is interested in gaining relevant information and drawing conclusion on the findings of the research work. For the purpose of the study, the target population was the pre-service teachers of Berekum College of Education and JHS pupils of the Berekum College Practice School. The population was 250 made up of 200 student-teachers and 50 pupils.

\section{Sample and Sampling Procedures}

Random sampling is the type whereby every member or unit of a population has equal chance of being selected for the required sample. It does limit the probability of choosing a bias sample. The researcher therefore used random sampling procedure so as to enhance the validity and generalisation of the result.Out of the 250 population of student-teachers and pupils, the researcher employed random sampling technique to select 50 student-teachers and JHS2 pupils as sample for the study. Thus, a written 'Yes' and 'No' on piece of papers folded with the 'Yes' totalling 50 copies and the rest with the 'No' were distributed among the student-teachers to pick one at a time in turns until all the piece of papers got finished. At the end, the 50 student-teachers who picked the piece of papers with 'Yes' written on were selected for the study. This was because the entire 250 population was considered too big for the study. The researcher therefore centred the research study on only the 50 student-teachers and JHS2 pupils to the whole of the population on the project since the researcher could not grant audience and observed all the teaching practices of all the 200 student-teachers with their pupils at the Berekum College Practice School.

\section{Instrumentation}

In order to have access to relevant data collection, the major instruments which included the observation of studentteachers teaching practices, model teaching by the researcher on the use of Cuisenaire Rods in the teaching and learning of common fraction, questionnaires for soliciting information on the effectiveness of the use of the Cuisenaire Rods, and interview granted to pupils on the study of common fraction with the use of Cuisenaire Rods were used for the study.

\section{Observation}

Observation refers to the situation whereby the researcher fails to take active part in the activities that takes place but only observe what actually takes place. I observed my student-teachers' teaching through macro-teaching and on-campus teaching practice. During on-campus teaching practice, the researcher only took notices of what the pre-service teachers did, especially when teaching common fraction in mathematics lesson, without taking any active part in these activities. One major advantage for using observation as an instrument for this study was that it helped the researcher to obtain first-hand information.

\section{Questionnaire}

With the employment of this instrument, 10 items of questionnaires were used to further solicit information confidentially from the pre-service teachers in order to adequately find answers to the research questions so that the core goal or purpose of the study can be realized. In relation to this, the questionnaires were, in the first place, set to identify the difficulties pre-service teachers have with the use of physical manipulative in teaching mathematics topics especially using Cuisenaire Rods to teach common fraction at the basic schools. Secondly, the questionnaires were set to identify the following outcomes:

a) The level of pupils' participation and understanding of concept of common fraction when using physical manipulative such as Cuisenaire Rods, and

b) The level of pupils' participation and understanding of concept of common fraction when using traditional method of 'talk and chalk' where fractional rules are applied in the teaching and learning common fraction during the lesson presentation.

The questionnaire approach was appropriate because it generated responses to some set of issues raised in the study. It again limited them to specific information needed through the use of close and open ended questions. The sample of items of the questionnaires can be found in Appendix 'A'.

\section{Interview}

Another instrument used by the researcher to collect data for the study was interview. Thus, to adequately have a complete data collection for the study, the pupils of JHS2 were specifically interviewed to ascertain their level of understanding on the use of concrete materials such as the use of Cuisenaire Rods in the teaching and learning of mathematics, especially on the study of common fractions during mathematics lessons. The items on the interview 
schedule were both structured and unstructured. The structured items elicited 'YES' or 'NO' responses from the pupils. The unstructured items allowed the pupils the freedom to express their views.

\section{Intervention Procedure}

Based on the information collected through the above mentioned instruments, the researcher employed a number of intervention strategies to improve the mathematics teaching in the basic school. Thus, pre-intervention, intervention and post-intervention activities were used to help improve pre-service teachers in the teaching of common fractions using Cuisenaire Rods in the basic school.

\section{Pre-intervention activities}

One important strategy employed by the researcher was the use of micro-teaching during student-teachers' oncampus teaching practices. During the on-campus teaching practice, student-teachers were grouped into two classes with 25 in number. Within each class, five smaller groups of 5 were made to prepare lessons on common fractions. Acting as a supervisor, the researcher sat to critically observe the presentations of student-teachers as they teach in turns whilst their class mates act as pupils in a mathematics class. This activities provide the opportunity to obtain first-hand information of the background knowledge of the pre-service teachers on the basic concept of common fractions and how they in-turn impart into the pupils during their teachings.

Without relying on what other people have said the following were some of the observations made.

- Some student-teachers never used any teaching and learning materials in their lesson presentations. Thus, mathematics lessons were presented orally.

- The student-teachers, at certain times in their lesson presentation, work out few examples on the chalkboard for the pupils to observe and also solve some few examples on their own.

- The pupils were not actively involved in the mathematics lessons.

- Few pupils were able to solve the problems they were normally asked to solve and majority of the pupils usually scored either zero or one.

\section{Intervention Activities}

Based on the information collected through the above mention instruments, the researcher planned a number of strategies in the form of workshops where model teaching with the use of Cuisenaire Rods in the teaching and learning of common fractions were employed. This intervention were meant to allow student-teachers assess the effectiveness of using physical manipulative, especially the use of Cuisenaire Rods in teaching the basic operations of common fractions by using the activity oriented approach. The researcher used two weeks for model teachings after which the student-teachers were allowed one week to re-teach their lessons with the prepared notes of teaching common fractions to their class mates during the macro-teaching practice on campus and then went ahead to teach pupils the same lessons using Cuisenaire Rods at the College Practiced School. The following stages of model teachings were organised to present lessons on basic operations of common fractions using Cuisenaire Rods.

\section{Relationships Study Stage}

To begin with, students were first introduced to see and know which Cuisenaire Rods is bigger than other and by how much. For instance, showing fractions with the Cuisenaire Rods is to place one rod over the other to compare their size. Such activities included the following:

a) Students find a rod that is longer than dark green but shorter than orange. This involves oral work, with the teacher first giving the specifications, and then students can give the whole group or partner specifications. The colour and then the numeral name are used.

b) Students find a rod which is 3 times as long as the red, light green, or white.

c) Students find a rod longer than light green by the same amount as the purple is longer than the red, and so on.

d) Students identify the relationship of the white and red and light green Rods to the others. White is $1 / 2$ of red, $1 / 3$ of green, and $1 / 4$ of purple.

e) Students match trains of two different colours to the same length.

f) Worksheets using greater than, less than and equal symbols are used for independent activities.

g) Make number families. For example, show how many different ways there are to make trains which equal 8 or brown. Discuss combinations. Those who are ready to, write equations.

\section{Ground Rules Stage}

The next area of instruction is called Ground Rules or knowing the mechanics for placement of Rods for their use in naming a fraction, choosing the Least Common Denominator, and adding and subtracting fractions. 


\section{Naming Fractions}

The standard method of showing fractions with the Cuisenaire Rods is to place one rod over the other to compare their sizes. The Rods can be shown vertically or horizontally. For example: using Cuisenaire Rods to represent $1 / 2$ and $3 / 4$ red rod and purple rod are taken as the denominators, white and light green as the numerators for the fractions $1 / 2$ and $3 / 4$ respectively.For $1 / 2$, since 1 white rod equals $1 \mathrm{~cm}$, the numerator and the denominator are multiplied by 1 white rod in order to have the fraction in equivalent terms.

Take the numerator $1 * 1$ white $\operatorname{rod}=1$

Take the denominator $2 * 1$ white $\operatorname{rod}=2$

So representing $1 / 2$ by using red rod as the denominator is shown below.

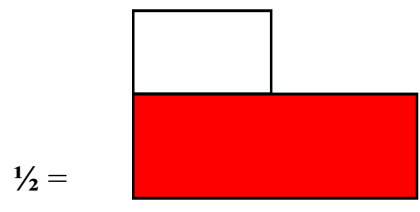

For $3 / 4$, since 1 purple rod equals $4 \mathrm{~cm}$, the numerator and denominator are multiplied by 1 purple rod in order to have the fraction in equivalent terms.

Take the numerator $3 * 1$ purple rod $=3$

Take the denominator $4 * 1$ purple rod $=4$

So representing $3 / 4$ by using purple rod as the denominator is shown below.

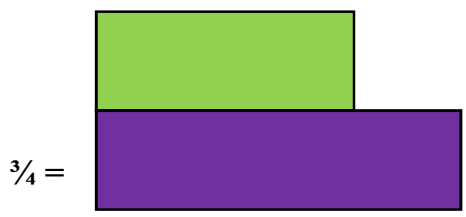

\section{Least Common Denominator (LCD)}

To solve problems with fractions, it is appropriate to first have a least common denominator (also sometimes called Least Common Multiple) of the fractions in question. If the LCD is not obvious, a rod that is a multiple of each denominator is sorted to work out the problem. For example: To find the Least Common Denominator for the fractions $1 / 4$ and $2 / 3$ Rods which represent both of the denominators are first chosen. In this case the denominator 4 is represented by the purple rod and the denominator $\mathbf{3}$ is also represented by the light green rod. Now a train of purple Rods and a train of light green are created (Rods lined up end-to-end) until they are equal in length. These trains are also known as multiples. Once the trains are created which equal in length total the number of centimetres in each train. As indicated below, 3 purple Rods $=12 \mathrm{~cm}$ and 4 light green Rods $=12 \mathrm{~cm}$. Therefore, the common denominator is $\mathbf{1 2}$.

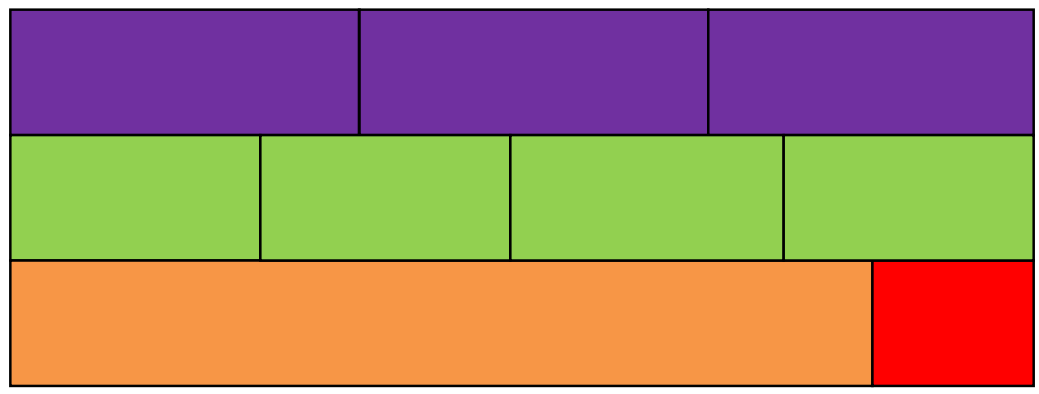

\section{3 multiples of 4}

4 multiples of 3

$12=$ LCD of $4 \& 3$

\section{Addition of Common Fractions}

Place the Rods end to end, moving left to right to make a train; find a single rod to match the length of the train. The addends are the cars of the train. The sum is the rod placed beneath the addend train. If the addend train is longer than orange, match it with a train made of as many orange Rods as will fit and whatever smaller rod will fill out the length of the train. For example: To add the fractions $1 / 2+1 / 3$ Rods are chosen to represent both of the denominators. The denominator $\mathbf{2}$ is represented by the red rod and the denominator $\mathbf{3}$ is represented by the light green rod. Now a train of red Rods and a train of light green are created (Rods lined up end-to-end) until they are equal in length. These trains are also known as multiples. Once the trains are created which equal in length total the number of centimetres in each train. As indicated below, 3 red Rods $=6 \mathrm{~cm}$ and 2 light green Rods $=6 \mathrm{~cm}$. Therefore, the common denominator is 6. 


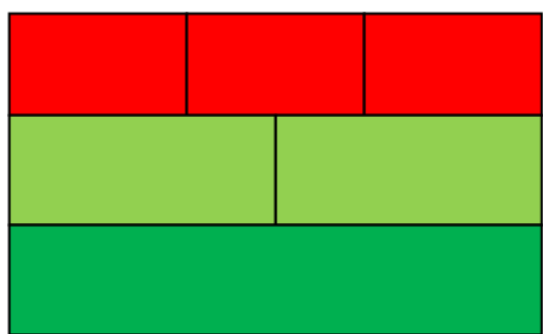

\section{3 multiples of 2}

\section{2 multiples of 3}

\section{$6=L C D$ of $2 \& 32$}

At this stage, each fraction is changed into the terms of the common denominator. Thus, the numerator of each fraction is multiplied by the number of Rods it takes to find the Least Common Denominator, i.e.

$1 / 2=$ take the numerator $1 * 3$ red Rods $=3 / 6$

$1 / 3=$ take the numerator $1 * 2$ light green Rods $=\mathbf{2} / \mathbf{6}$

Now, having the common terms the numerators are just added

$3 / 6+2 / 6=5 / 6$

\section{Subtraction of Common Fractions}

Place the smaller rod on top of the larger one and see what rod is needed to make a matching train or fill the gap. Place the subtrahend on top of the minuend, and the difference is that rod which fills up the space. In terms of fractions, common denominator is first identified in order to determine which train of Rods would equal the length of rod of the denominator. For example: To solve the problem, $1 / 2-1 / 8$ Rods are chosen to represent both denominators. In this case, red for $\mathbf{2}$ and brown for $\mathbf{8}$ are used. At this stage, trains of Rods are made to have Rods of equal length. With this, the common denominator is $\mathbf{8}$.

Again, each fraction is changed into the terms of the common denominator. Thus, the numerator of each fraction is multiplied by the number of Rods it takes to find the Least Common Denominator, i.e.

$1 / 2=$ take the numerator $1 * 4$ red Rods $=\mathbf{4 / 8}$

$1 / 8=$ take the numerator $1 * 1$ brown $\operatorname{rod}=\mathbf{1 / 8}$

Now, having the common terms the numerators are just added

$4 / 8-1 / 8=3 / 8$

\section{Post-Intervention}

Having taken student-teachers through a number of fraction lessons as sample of such activities have been shown above in the intervention stage, it was found that participants were actively involved in the lesson presentation. Student-teachers then delivered their lessons in a macro-teaching practice where almost all the problems observed during the pre-intervention activities were adequately addressed. In addition, the student-teachers were made to present their prepared lessons on fractions to the JHS2 pupils at the College Practice School. By comparison, the pre-service teachers discovered that the use of the Cuisenaire Rods in the teaching of common fractions has actually aroused their interest in using physical manipulatives in mathematics lesson delivery, especially teaching common fractions.

\section{Data Collection Procedure}

The assistance of colleagues as well as the permission to administer the questionnaires at Berekum College of Education was officially sought from the college principal. In addition, the researcher officially sought permission from the Head-teacher of the College Practice School before using the JHS2 pupils for the teaching sessions and interviews as well.

The questionnaires were distributed to the pre-service teachers to provide their responses within one week period of collection. All the 10 completed questionnaires were retrieved after the one week period which did not disrupt the instructional activities of the College. With the questionnaires, the first 1-3 items of the questions were set to assess the pre-service teachers the difficulties they face with the use of concrete materials in their mathematics lessons, especially using Cuisenaire Rods in teaching common fractions. The other 4-7 items of the questions were structured to measure the extent of pupils' participation and understanding of teaching and learning of common fractions when using Cuisenaire Rods. The rest of the items were structured to similarly measure level of pupils' participation and understanding of the mathematics lesson when using fractional rules in the teaching and learning of common fractions.

An interview schedule was used for the study. The items on the schedule were both structured and unstructured. The structured items elicited 'YES' or 'NO' responses from the pupils. The unstructured items allowed the pupils the freedom to express their views. The items on the interview schedule are displayed in Appendix 'C'. 


\section{Validity and Reliability of Instruments}

To ensure reliability of the instruments used, the research questionnaires were set in consonant with the research questions thereby giving the researcher the direct focus as to what the study was designed to look for. In this connection, the items in the questionnaires were drafted in simple words for easy understanding so that the studentteachers respond to the questions without difficulty. For the validity of the instrument used, the questionnaire was administered under the supervision of the College Assessment Officer and other colleagues. In addition, the researcher ensured that the questionnaires were distributed to the sampled population personally and also followed up in retrieving the sent questionnaires with responses.

\section{Data Analysis Procedure}

The researcher made used of statistical methods to analyze the data collected. Each question was analyzed and the number of respondents who gave particular responses was recorded. Descriptive statistics in terms of frequencies with their percentages were used in analysing the data obtained from the questionnaire. Again, descriptive statistics were used to illustrate and interpret the research findings.

\section{Presentation of results}

Out of all the 50 completed questionnaires distributed, the researcher was able to retrieve all of them from the sampled population within the one week period without much difficulty since the exercise was aided by my colleagues in the college. The responses to the questionnaires are statistically displayed and their corresponding outcomes analyzed after the tables below. Additionally, the total number of responses used in analyzing and interpreting the data vary, depending upon the case being studied.The first three tables 1, 2 and 3 sought to assess the difficulties student-teachers face with the use of concrete models such as Cuisenaire Rods in teaching common fractions and how often these models are used in their mathematics lessons.

Do you use concrete models/materials in your mathematics lessons?

Table 1 Responses on whether pre-service teachers use models in their mathematics lessons

\begin{tabular}{lcl} 
ITEM & FREQUENCY & PERCENT \\
\hline & & \\
Yes & 44 & 88.0 \\
No & 6 & 12.0 \\
Total & $\mathbf{5 0}$ & $\mathbf{1 0 0 . 0}$
\end{tabular}

From table $4.2,88 \%$ of the respondents asserted to the use of concrete models in their mathematics lessons whilst 6 of the respondents representing 12\% still felt mathematics lessons can go on without using concrete models. This reveals that majority of our pre-service teachers do use concrete models in their mathematics lessons. Hence, there is no doubt that the pre-service programmes designed to prepare the would be teachers, in the Teacher Education Institutions, should focus on critical study of themes and direct experiences that help teachers understand the sociological influences which affect students (Feiman-Nemser, 1990).

In which of the following ways do you find the use of Cuisenaire Rods challenging in the teaching of common fractions?

Table 2 Responses on how the pre-service teachers find the use of Cuisenaire Rods challenging in the teaching of common fractions.

ITEM

Developing the concept of common fractions

Operations on common fractions

If other, specify

Total

\section{FREQUENCY}

34

15

1

50

\section{PERCENT}

68.0

30.0

100.0

With regard to table $4.3,34$ student-teachers representing $68 \%$ found the use of Cuisenaire Rods much challenging when using the models to teach pupils on how to develop the concept of common fraction, whilst $30 \%$ of the respondents experienced the challenge in treating the operations on common fractions with children. This reveals that the mind-set of the student-teachers of mathematics teaching must clearly be defined. In other words, they would be teacher should be properly trained to be the best facilitator who provides learning opportunities that learners create and build their own understanding of the topics they study, rather than having it delivered to them by teachers. However, the student-teachers can only be the best facilitator when his/her pupils are engaged in 
hands-on activities where physical manipulatives, such as Cuisenaire Rods, can be used to help children of all ages construct a deeper understanding of mathematical concepts (Clement \&McMillen, 1996).

How often do you use Cuisenaire Rods in the teaching of common fractions in your class? Table 3 Responses on how often do student-teachers use Cuisenaire Rods in teaching common fractions. ITEM FREQUENCY PERCENT

$\begin{array}{lcc}\text { Always } & 1 & 2.0 \\ \text { Sometimes } & 43 & 86.0 \\ \text { Not at all } & 6 & 12.0 \\ \text { Total } & \mathbf{5 0} & \mathbf{1 0 0 . 0}\end{array}$

From table 4.4 , about $88 \%$ of the respondents use Cuisenaire Rods to teach common fractions whilst the rest of the student-teachers do not use the models in teaching common fractions at all. This reveals that there is appreciable number of student-teachers who see the significant impact of using Cuisenaire Rods in their mathematics teaching. Therefore, this resultant evidence from the table goes to support the research findings made by Butler et. al. (2003) and Marsh et. al. (1996) states that the use of Cuisenaire Rods needs to be integrated into the school curriculum and not only use as an adjunct activity. Thus, the manipulatives must be used wisely to provide students with opportunities for guided exploration helping them to build a social understanding of mathematical concepts.

The next four tables 4, 5, 6 and 7 sought to measure the extent of pupils' participation and understanding of teaching and learning of common fractions when using either Cuisenaire Rods or Fractional Rules.

How effective is the participation of your pupils in class when using Cuisenaire Rods in teaching common fractions?

Table 4Responses on the effective participation of pupils in class when Cuisenaire Rods were used to teach common fractions

\begin{tabular}{lll} 
ITEM & FREQUENCY & PERCENT \\
\hline & & \\
Very effective & 8 & 16.0 \\
Effective & 37 & 74.0 \\
Less effective & 5 & 10.0 \\
Total & $\mathbf{5 0}$ & $\mathbf{1 0 0 . 0}$ \\
\hline
\end{tabular}

Table 4 shows that $90 \%$ of the student-teachers experience pupils' active participation in their mathematics lessons whenever they use Cuisenaire Rods as their teaching aids, especially when treating common fractions. However, the $5 \%$ of the remaining respondents does not experience such active participation from the pupils in their mathematics lessons. This result therefore tends to reveal that if majority of pupils in our schools are properly introduced to the usage of manipulatives during mathematics lessons, they would perceive these concrete materials as something fun and interesting. Such situations make pupils tend to enjoy mathematics more, and they are able to succeed in achieving greater heights in mathematics studies.

How do you assess the use of Cuisenaire Rods in teaching common fractions in your class?

Table 5 Responses on the assessment of using Cuisenaire Rods by the pre-service teachers when teaching common fractions.

\begin{tabular}{lcl} 
ITEM & FREQUENCY & PERCENT \\
\hline & & \\
Very effective & 16 & 32.0 \\
Effective & 30 & 60.0 \\
Less effective & 4 & 8.0 \\
Total & $\mathbf{5 0}$ & $\mathbf{1 0 0 . 0}$ \\
\hline
\end{tabular}

A look at table 4.6 shows that student-teachers found the use of Cuisenaire Rods in teaching common fractions to be very effective, since $92 \%$ of the respondents felt very comfortable with the use of the concrete models in their mathematics lessons. These results go to support the research findings made by Lesh (1979) that a lot of people are hands-on learners and it helps a lot of students to be able to work with something they can understand. Thus, manipulatives, especially using Cuisenaire Rods, work well in co-operative learning which allow students 
to take a more active role in classroom experiences; empowering students to not only learn, but teach also.

How effective is the participation of your pupils in class when using Fractional Rules in teaching common fractions?

Table 6 Responses on the effective participation of pupils in class when fractional rules are used to teach common fractions

ITEM

Very effective

Effective

Less effective

Total

A look at table 6 shows that out of 50 respondents, $72 \%$ affirmed that pupils in their mathematics lessons do not actively involve themselves in the lessons presentation, since the use of rules becomes the medium of instruction in teaching common fraction which they hardly find it easy to understand the concept being taught. This outcome can be likened to the assertion made by Peck and Jenecks (1981) that the practice of using rules in the study of fractions has revealed that traditional fraction-arithmetic instruction usually focuses on 'how' not on 'why'. As a result, most children cannot give plausible justifications for the procedures they use.

How do you assess the use of Fractional Rules in teaching common fractions in your class?

Table 7 Responses on the assessment of using Fractional Rules by the pre-service teachers when teaching common fractions.

\begin{tabular}{lcc} 
ITEM & FREQUENY & PERCEN \\
\hline & & \\
Very effective & 3 & 6.0 \\
Effective & 11 & 22.0 \\
Less effective & 36 & 72.0 \\
Total & $\mathbf{5 0}$ & $\mathbf{1 0 0 . 0}$ \\
\hline
\end{tabular}

Table 7 shows that 36 out of 50 respondents admitted that the use of rules in teaching common fractions tend to steal out the active environment that student always wish to experience during the lesson presentation. Thus, the use of rules of learning fractions eventually makes it difficult for students or pupils to learn it. Here, pupils simply try to memorize the fractional rules without knowing where they came from, and these rules would probably seem like a jungle of seemingly meaningful rules. Reflecting on this result, Ball et al (2001) research findings came out that teachers are less confident and less successful in teaching rational numbers than whole numbers. This is simply because whiles a number of fresh practicing teachers struggle with basic computations of fractions; others made errors in trying to apply rules. The rest of the tables 8,9 and 10 also sought to measure studentteachers' preference of using either the Cuisenaire Rods or fractional rules in teaching common fractions, and the extent to which the use of Cuisenaire Rods can help improve pre-service teachers in their mathematics teaching practices.

Which of the following do you prefer using in teaching the concept of common fractions?

Table 8 Responses on the preference of using either Fractional Rules or Cuisenaire Rods in teaching the concept of common fractions

\begin{tabular}{lll} 
Item & Frequency & Percent \\
\hline Fractional rules & 10 & 20.0 \\
Cuisenaire Rods & 40 & 80.0 \\
Total & $\mathbf{5 0}$ & $\mathbf{1 0 0 . 0}$ \\
\hline
\end{tabular}

A look at table 8 shows that $80 \%$ of the respondents prefer using Cuisenaire Rods in teaching common fractions whiles $20 \%$ use rules in teaching fractions in their mathematics lessons. This result is an indication that both teachers and pupils evaluated the effectiveness of using concrete models as tools in mathematics learning. Additionally, student-teachers prefer the usage of Cuisenaire Rods to fractional rules because the Rods serve as manipulatives which help pupils improve their understanding of the abstract symbolic language of mathematics. Thus, the concrete manipulatives are used to clarify misconception and build connection between mathematical concepts and representations; fostering more precise and richer understanding. 
Which of the following teaching strategies do improve your pupils' achievement in the study of common fractions?

Table 9 Responses on the strategies pre-service teachers can use to help pupils perform better in the study of common fractions

ITEM

FREQUENCY

PERCENT

Using fractional rules

10

20.0

Using Cuisenaire Rods

40

80.0

Total

50

100.0

Table 9 also shows that $80 \%$ of the respondents affirmed on the fact that using Cuisenaire Rods in mathematics lesson go a long way to help pupils understanding abstract concepts which are represented concretely during mathematics learning in class and linking these concepts to prior knowledge. This result goes to support the findings made by Lesh (1979) that the use of physical manipulatives tend to promote problem-solving ability by providing a vehicle through which children can model real-world situations.

To what extent do you agree that the use of Cuisenaire Rods does improve pre-service teachers' teaching practices especially in their mathematical lessons?

Table 10 Responses on the extent to which the use of Cuisenaire Rods does improve pre-service teachers' teaching practices in their mathematical lessons

ITEM FREQUENCY

PERCENT

Very much agreed

13

26.0

Agreed

Do not agreed

36

72.0

Total

50

2.0

100.0

Table 4.11 shows that $98 \%$ of the respondents were much convinced and agreed that the use of concrete models, especially using Cuisenaire Rods does improve their teaching practices in mathematics classroom. A quick reflection on most responses given by the student-teachers to the questionnaire showed that the use of such manipulatives make students tend to enjoy mathematics more and they are bound to succeed in the pursuit of further studies in mathematics. Also, the responses from the student-teachers on this table are not farfetched as compared to the research findings made by Dienes (1971) that pupils' experiences with these concrete models which are carefully selected by the classroom teacher do form the cornerstone upon which all mathematics learning is based.

\section{Discussion of Findings}

A critical look at the analysis done on the data collected showed that pre-service teachers' pedagogical-content knowledge on the use of Cuisenaire Rods in teaching common fractions are generally positive. Even though the initial usage of the Cuisenaire Rods by the pre-service teachers seemed to be much challenging, the aftermath of the researcher's two-week model teaching as the intervention strategy changed the unfriendly attitudes and misconception student-teachers had on the usage of the Rods. In the first place, pre-service teachers used to present their mathematics lesson orally. Thus, they hardly use concrete models in their lessons, but from the time of intervention period, pre-service teachers came to appreciate the significant use of the Rods and accordingly adjusted to the usage of the Rods in their mathematics lessons.

Also, before the intervention sessions, pupils were not actively involved in the mathematics lessons, but the results from the data collected showed that student-teachers found the use of Cuisenaire Rods in teaching common fractions to be very effective. Hence, pupils were found to be at ease working with the concrete models during mathematics lessons. The researchers view point hast it that if students are properly introduced to the usage of manipulatives during mathematics lessons, they would perceive these concrete materials as something fun and interesting. Such situations make students tend to enjoy mathematics more and they are able to succeed, so it is especially helpful for students who traditionally fail or struggle in mathematics class.

In addition, the results revealed so far, tend to suggest that in pre-service mathematics learning environment, student-teachers should be provided with ample learning opportunities to practice their mathematics skills. Also, more often than not, they need to know more about different classroom teaching and learning techniques that can be used on how to create participatory lessons that motivate children to keep them engaged in their classes.

Results from the analysis done on the need of using concrete models to teach mathematics topics, especially common fractions at the basic schools go to affirm the research findings of Butler et al (2003) and Marsh et al (1996), that the use of Cuisenaire Rods need to be integrated into the school curriculum and not used as an adjunct activity, thus, the manipulatives must be used wisely to provide students with opportunities for guided exploration 
helping them to build a solid understanding of mathematical concepts.

In a nutshell, the findings again showed that student-teachers should engaged their pupils in more active teaching strategies in solving problems of fractions. With this activity method of teaching, pupils would be able to examine a problem, examine their resources and find ways in which resources can be used to meet the demands of the problem. The results have strongly revealed here that most people are hands-on learners from the point view that of their informal knowledge that has been developed at home before schooling. It is therefore hope that pupils can be helped to build a strong conceptual base upon which they can rely, if Cuisenaire Rods are used to develop their quantitative understanding before symbolic ideas on common fractions are introduced, especially during early days of their basic education.

\section{Summary, Conclusion and Recommendations Overview of the Study}

The study aimed at improving pre-service teachers teaching practices on using Cuisenaire Rods to teach common fractions at the basic schools in Ghana. This study was designed among other things, to test the effectiveness of using Fractional Rules as against using Cuisenaire Rods in the teaching and learning of common fractions. In addition, the study sought to assess the extent of pupils' participation in mathematics learning when using fractional rules or Cuisenaire Rods. Moreover, the study further sought to find student-teachers' views on the extent to which Cuisenaire Rods did improve their teaching practices during mathematics lessons. Since the study of the basic concepts in mathematics is required at the basic level in our schools, the research work was conducted to ensure that student-teachers' teaching practices provide a good foundation in mathematics especially on the basic operations on common fractions.

Again, the study sought to develop the type of experiences that could assist beginning teachers provide contextual teaching strategies where pupils can construct their own understanding in the study of mathematics. Thus, the study was conducted to improve beginning teachers with practice base knowledge that could serve as an effective vehicle for the translation of theory base knowledge into activity oriented technique of learning where pupils' interest can be guaranteed to study mathematics, particularly on common fraction, without much difficulty. Aside the aims and purpose of the study, the research work was guided by the following research questions:

- How can the use of Cuisenaire Rods improve pre-service diploma teachers' performance in the teaching of common fraction?

- What types of teaching practices are needed by the pre-service teachers in order to overcome pupils' difficulties in the study of common fraction?

- What difficulties do pre-service teachers face in using Cuisenaire Rods to teach common fractions?

- To what extent can the use of Cuisenaire Rods by the pre-service teachers help improve pupils' mathematics achievement in the study of common fraction?

Observation, in the first place was one important strategy used by the researcher to obtain first-hand information of the background knowledge of the pre-service teachers' teaching techniques on the development of basic concept of common fractions with their pupils during mathematics lessons at the practiced basic schools.

Research questionnaire and interviews were among the research instruments used to collect relevant data for the research work. For effective research work fifty questionnaire were distributed to solicit the relevant information from the pre-service teachers, having carried out the research intervention activities.

Model teaching was adopted by the researcher as the intervention strategy used to prepare student-teachers on how effective the use of Cuisenaire Rods could be carried out successfully to teach and learn common fractions in the mathematics class.

\section{Summary of Major Findings}

The research study revealed that pupils respond positively towards mathematics studies whenever they are given the opportunities to construct their own meaning during the lesson presentation in class. Thus, their responses to the use of Cuisenaire Rods in the study of common fractions were full of encouragement. It was again found that the student-teachers who were earlier on solely relied on the use of rules in teaching common fraction, changed to teach common fraction and any other mathematics basic concepts by using concrete models as an instructional activity. Moreover, the findings established that hands-on activity, such as the use of Cuisenaire Rods in mathematics learning possess potential to reach out to pupils for whom mathematics has hold little attraction. This goes to support the findings made by Clements and McMillen (1996) that the use of physical manipulatives can help children of all ages construct a deeper understanding of mathematics. More importantly, the research showed that when the mind-sets of the pre-service diploma students are channelled in a professional way, they would tend to be reflective individuals who take ownership of their ideas and see them through from conceptualization to reality. This finding is strongly supported by Shulman (1987), who contended that pedagogical-content knowledge has to do with the knowledge teachers need to have about teaching and students to teach effectively and more so be the trustworthy facilitator in classroom learning by promoting positive classroom atmosphere. 


\section{Implications for Practice}

With respect to the in-depth analysis and discussions of the data collected, the major findings of the study have revealed the following educational implications:

- The use of physical manipulatives (Cuisenaire Rods) can play a role in students' construction of meaningful ideas. They should be used before formal instruction, such as teaching algorithms. However, teachers and students should avoid using manipulatives as an end but rather than as a means to that end.

- The above implication is in agreement to Suh and Moyer (2007) who contended that although physical manipulatives are used primarily in elementary schools, they offer a useful means to introduce new concepts to all students when teachers make this meaning explicit and help students build connections between the concrete materials and the abstract symbols that they represent

- The supply of mathematics syllabus into the Colleges of Education should be accompanied with adequate teaching and learning aids for pre-service teachers to receive sufficient pre-training in all aspects of the curriculum before becoming professional teachers to avoid gambling with the young on whom the future of the nation rests. In line with this educational implication, Feiman-Nemser (1990), stated that the preservice programmes designed to prepare the would be teachers should focus on critical study of themes and direct experiences that help teachers understand the sociological influences which affect students in their subject area.

- Pupils should be encouraged to use manipulatives to solve a variety of problems and then to reflect on and justify their solutions. Thus, such varied experience and justification helps students build and maintain understanding. Thereby developing positive attitudes toward mathematics, when instructions on the use of the manipulatives are improved by the teacher. In agreement to this educational implication, Shulman (1987) contended that pedagogical-content knowledge has to do with the knowledge teachers need to have about teaching and students to teach effectively and more so be the trustworthy facilitator in classroom learning by promoting positive classroom atmosphere.

\section{Conclusion}

Upon critical analysis and interpretation of the data, the following conclusions have been drawn:Student-teachers who resort to the use of rules of teaching and learning common fractions make their pupils to memorize these rules without knowing where they came from, and these rules would probably seem like a jungle of seemingly meaningless rules. Student-teachers experience less participation in their mathematics class whenever fractional rules are used in teaching common fractions.Pupils are highly motivated to actively partake in learning basic concepts in mathematics whenever concrete models are used in the lesson presentation. Thus, these manipulatives, such as using the Cuisenaire Rods tend to make the lesson interesting and easy for both teachers and pupils. Student-teachers who adopt a variety of hands-on activities to the teaching and learning of mathematics tends to create ample opportunities for learners to observe, notice, hypothesizes, practice and eventually internalize the basic concepts learnt in mathematics much more understanding. Logically, no matter how different the present and future teachers are prepared in our various Colleges of Education; the competencies of teacher education in our contemporary world would much depend on student-teachers' teaching methods and teaching practices that can bring real meaning into the lives of their pupils.

\section{Recommendations}

Based on the major findings emanating from the research work, I wish to come up with the following recommendations that can bring improvement in pre-service teachers teaching practices and quality mathematics education in our basic schools.

a. Since all children are naturally hands-on learners, pre-service teachers should purposely be given the right training sessions on classroom teaching practices to provide environment that would motivate pupils to build their confidence in doing mathematics.

b. Mathematics plays a leading and service role in all aspect of human endeavours. The basic school mathematics curriculum should, therefore, provide children with stimulating and wide-range of mathematical learning experiences that would develop their skills and knowledge which would eventually enable them to function as useful citizens.

c. It is also recommended that the use of Cuisenaire Rods need to be integrated into the basic school curriculum and not use as an adjunct activity. Thus, the manipulatives must be used wisely to provide students with opportunities for guided exploration helping them to build a solid understanding of mathematical concepts.

\section{Suggestions for Further Research}

A critical look into the pre-service teachers' teaching practices on basic concepts in mathematics is quite interesting and challenging task.It is therefore suggested that whoever takes up the challenge to carry out a similar project 
should endeavour to select the sample population to cover two or more Colleges of Educations in Ghana.Moreover, any further researcher should try to direct his/her research work into encouraging pre-service mathematics teachers to switch from the transmission approach of mathematics teaching to activity-based approaches.

Acknowledgements: Dr. IssifuYidana of the Mathematics Department, University of Education Winneba, Mr. Yaw Adjei-Sarkodie, the Principal of Berekum College of Education,Mrs. Sekyeraa Amoah and my two lovely daughters: Emmanuella Akua Seinti and Patience Akosua Afrakoma.

\section{References}

Anderson, Cindy, L., Kevin, M. Anderson, \& Edward, J., Wenzel (2000). Oil and water don't mix, but they do teach fractions. Teaching children mathematics 7, 174-78.

Ball, D. (1992). Magical hopes: Manipulatives and the reform of math education. America Educator, 16, 14-18.

Ball, D., L. (1989). Breakingwith experience: Therole of a pre-service methods course. Michigan State University: National Centre for Research on teacher Education.

Ball, D. L., et. al. (2001). Research on teaching mathematics: The unsolved problem of teachers' mathematical knowledge. In V. Richardson (ed.). Handbook of research on teaching, (pp. 433-456). Washington, D.C: America Educational Research Association.

Baroody, A. J. (1987). Children's mathematical thinking: A development framework for preschool, primary, and special education teachers. New York: Teachers College Press.

Butler, F. M. Crehan, K. Babbitt, B., \& Piece, T. (2003). Fraction instruction for students with mathematics disabilities: Comparing two teaching sequences Learning Disabilities Research and Practice, 18(2), 99-111.

Clements, D. H. \&McMillen, S. (1996). Rethinking concrete manipulatives: Teaching children mathematics, 2(5), 99-111.

Cramer, K. A., Post, T. R., \&delMas, R. C. (2002). Initial fraction learning by fourth-and- fifth grade students: a comparison of the effects of using commercial curricula with the effects of using the rational number project curriculum. Journal for Research in Mathematics Education, 33(2), 111.

Cramer, K., \& Henry, A. (2002).Using manipulative models to build number sense for addition of fractions. NCTM 2002 yearbook: Making sense of fractions, ratios and proportions, (pp 41-48).

Dienes, Z. P. (1969). Building up mathematics. (rev. ed.). London: Hutchinson Educational.

Dienes, Z. P. (1971). An example of the passage from the concrete to the manipulation of formal systems: Educational studies in mathematics, (pp. 337-352).

Dienes, Z. P., \& Golding, E. W. (1971).Approach to modern mathematics. New York: Herder and Herder.

Feiman-Nemser, S. (1983).Learning to teach. L. Shulman \& G. Sykes (eds.). Handbook of teaching and policy, (p. 150-1700). New York: Longman.

Feiman-Nemser, S., \&Buchmann, M. (1985). Pitfalls of experience in teacher preparation: Teachers college record, 87(53-65).

Goldin, G., \&Shteingold, N. (2001). Systems ofrepresentations and the development of mathematical concepts: In A. Cuoco\& F. R. Curcio (eds.). The roles of representation in school mathematics, (pp. 1-23).

Gravemeijer, K. P. E. (1991). Aninstruction-theoretical reflection on the use of manipulatives: In realistic mathematics education in primary school. The netherlands: freudenthal institute, Utrecht University.

Kamii, C. (1985). Young children reinvent arithmetic: Implications of Piaget's theory. New York: Teachers College Press.

Kamii, C. (1986). Young children continue to reinvent arithmetic: $2^{\text {nd }}$ grade. implications of Piaget's theory. New York: Teachers College Press.

Kamii, C., \& Clark, F. B. (1995). Equivalent fractions: Their difficulties and educational implications. The journal of mathematics behaviour, 14(4), 365.

Lamon, S. J. (2006). Teaching fractions and ratios for understanding (2 ${ }^{\text {nd }}$ ed.). Mahwah, NJ: Lawrence Erlbaum Associates.

Lortie, D. (1975). Schoolteacher: A sociology study. London: University of Chicago Press.

Marsh, L. G., \& Cooke, N. L. (1996). The effects of using manipulatives in teaching math problem-solving to students with learning disabilities: Learning disabilities research and practice, 11(1), 58-65.

Martin, J. L. (1994). Mathematics for teacher training in ghana students' activities, Accra - North, Unimax.

Martin, J. L. (1994). Mathematics for teacher training in ghana tutor's Notes, Accra-North, Unimax.

Moyer, P. S. (2001). Are we having fun yet? How teachers use manipulatives to teach mathematics. Educational studies in mathematics: An international journal, 47(2), 175-195.

Nabie, M. J. et. al. (2000). A critical analysis of the policy practice of mathematics education in ghana: The journal of the mathematical association of ghana. Vol.12, 37-39.

Piaget, J. (1971). The psychology of intelligence. Boston: Routledge and Kegan.

Ploger, D., \& Rooney, M. (2005). Teaching fractions: Rules and reason.Teaching children mathematics. V12, 1217. 
Reys, R., Suydam, M., \& Lindquist, M. (1995).Helping children learn mathematics, Boston, MA: Allyn and Bacon.

Riddle, M., \& Bette Rodzwell (2000). Fractions: What happens between kindergarten and the army.Teaching children mathematics 7,202-6.

Rober, E. (1998).Children learning mathematics: Great Britain, Alden Press Ltd. Oxford.

Skemp, R. (1991). Mathematics in the primary school. Billing Sons Ltd: Worcester, UK.

Smith III, J.P. (2002). The development of students' 'knowledge of fractions and ratios, NCTM Yearbook: Making sense of fractions, ratios and proportions, (pp3-17).

Sowell, E. J. (1989). Effects of manipulative materials in mathematics instruction: Journal for research in mathematics education, 498-505.

Stein, M. K. \&Bovalino, J. W. (2001). Manipulatives: One piece of the puzzle. Mathematics teaching in the middle school, 6(6) 356-359

Thompson, P. W. (1990). Notations, conventions, and constraints: Contributions to effective use of concrete materials in elementary mathematics. Journal for research in mathematics education, 123-147.

Thompson, P. W., \& Alba, G. T. (1990).Salient aspects of experience with concrete manipulatives. International group for the psychology of mathematics education: Mexico City.

Wang, T. (2003).A critical review of the new constructivist math program under consideration by the oak ridge school system. Retrieved from http://www.lit.net/orschools/everydaymath2.htm.

Watson, W. H. (1980). Mathematics in school. Mathematical association publishers Ltd: London Road.

Wilensky, U. (1991). Abstract mediation on the concrete and concrete implications for mathematics education; in constructionist: Ablex Publishing Company. 